\title{
Construction of a Diversified Integrated Platform Based on Home Care Services
}

\author{
Jianghua He \\ Sichuan University of Arts and Science, Dazhou, China \\ Email: drifter626@163.com
}

How to cite this paper: He, J.H. (2019) Construction of a Diversified Integrated Platform Based on Home Care Services. Open Journal of Social Sciences, 7, 161-167. https://doi.org/10.4236/jss.2019.76013

Received: May 24, 2019

Accepted: June 21, 2019

Published: June 24, 2019

Copyright $\odot 2019$ by author(s) and Scientific Research Publishing Inc. This work is licensed under the Creative Commons Attribution International License (CC BY 4.0).

http://creativecommons.org/licenses/by/4.0/

\begin{abstract}
Facing the increasingly serious problem of an aging population and pension mode, the government put forward the main forms of family endowment in the process of practice how to work more effectively and efficiently, this paper proposed a multivariate comprehensive platform, uniting old man, society, family and government and service agencies, etc., to make the parties meet the needs of the old man to occupy the endowment service in a timely manner.
\end{abstract}

\section{Keywords}

Home-Based Care for the Aged, Care Services, Platform

\section{Introduction}

China is already facing the daunting challenge of an aging population. According to data released by the state council office on aging, China's population aged 60 and above reached 241 million in 2017, accounting for 17.3 percent of the country's total population. It is estimated that by 2020 , the number of people over the age of 60 will increase to about 255 million, accounting for $17.8 \%$ of the total population. The number of elderly people will increase to about 29 million, and the number of elderly people living alone or in empty nests will increase to about 118 million [1]. This figure far exceeds the definition of population aging by the international population association of the United Nations: that is, when the proportion of the population over 60 years old in a country or region reaches or exceeds $10 \%$ of the total population, the country enters an "aging society". In this context, the 2018 government work report puts forward the following proposals: actively respond to the aging population, develop home-based, community-based and mutually-assisted old-age care, promote the integration of medical care and old-age care, and improve the quality of old-age care services. After 
years of co-development of multiple modes of old-age care, the home-based, community-based and institution-supported pattern of "9073" old-age care service has been accepted and practiced: that is, in the future, $90 \%$ of the elderly in China will be home-based care, $7 \%$ will be community-based care, and $3 \%$ will be institutional care.

\section{Current Situation of Home Care Services}

At present, China's pension service industry is showing a change from positioning and qualitative to quantitative and qualitative. Change from single service supply to multiple service supply; From a single organizational form, to a variety of organizational forms and other characteristics; The transition from relying solely on children to social care-relying on community home care plays a bridging role. "9073" pension pattern is exactly the manifestation of this trend: its core meaning is the socialization of pension service, that is, the development direction of China's pension service will gradually change from the traditional family pension to the socialized pension characterized by specialization, humanization and industrialization.

The socialization and specialization of old-age care services refer to the purchase of home-based old-age care services by social professional organizations and enterprises funded by the government. Purchase contracts are signed between the government and enterprises or professional organizations for home-based old-age care services. Meanwhile, the government evaluates and supervises the purchased services in a certain way. In view of China's national conditions and the pattern of old-age care, the current home-based old-age care is mainly targeted at disabled elderly over 60 years old and elderly over 80 years old. However, due to the uneven development in different regions, it is difficult to ensure that all the funds are in place when the specific implementation is implemented. In some places, the purchase funds for home-based care services are only central funds, so it is difficult to guarantee the full coverage of the service items and service objects.

\section{Demand for Home Care Services}

Home-based care is a standardized old-age care service system that takes family as the carrier and community as the support, and provides life care, medical service, housekeeping service and spiritual comfort to the elderly living at home through door-to-door service and community day care, so as to meet the needs of the elderly at different levels. The biggest characteristic of home endowment service is to go to the door to undertake individual case service, make old people do not break away from oneself family this one familiar environment [2].

In the current service plan, home-based care services provided by enterprises or organizations are centralized rationing under the condition of fixed quantity, including service items and service time, service demand imbalance, service response untimely, service supervision not in place and service quality difficult to 
guarantee. If common to eat in the house, bath, help, help, help "five help" services such as medical, maybe old man because of living in remote mountainous area need to provide the medical emergency rescue service, but the reality is that service industry is already according to the individual (e.g., help) completed the total package contract value, in this case the old man can't enjoy family endowment service; At the same time, the completion of the contract should also be subject to the supervision of government departments, and the actual supervision is a sampling survey, so there is an accidental or artificial lack of supervision; Meanwhile, it is difficult for the society or the family members of the target to understand the real-time dynamic of the activity due to lack of information. Therefore, under the current situation of insufficient investment, unprofessional service and narrow coverage of home-based care services [3], it is urgent and necessary to establish a diversified platform integrating government, enterprises, service objects and regulatory departments to connect services, demands, supervision and feedback.

\section{Established a Management System for Home-Based Elderly Care Service}

With the development of society, the change of family structure and the arrival of the aging peak, the 13th five-year plan clearly points out that "a multi-level old-age care service system based on home, supported by community and supplemented by institutions should be established" [4]. So that occupy the home endowment service is based on family as the core, to the community, the specialized service as the main form, give play to the role of government-led, widely mobilize social forces, make full use of community resources to provide that occupy the home of the elderly life care, domestic service, rehabilitation care and spiritual comfort services such as a form of pension, it is to add and update the traditional family pension mode, is the development of community service in our country, establish endowment service system is an important content.

\subsection{Established a Home-Based Old-Age Care Service Network}

A three-level home-based old-age care service network covering the central urban area, streets and communities have been established, and the whole-coverage home-based old-age care service network has been realized for the streets and communities in the central urban area. Accelerate the construction of information management platform for home-based care services, comprehensively grasp the basic conditions, health conditions and service needs of the elderly and family members, and promote the effective connection between the information platform and home-based care service entities, so as to provide timely and convenient services for the elderly in need.

\subsection{Improved the Security System for Home-Based Care for the Elderly}

Lead the absorption of social service resources and economic entities into pension 
services, effective service aggregation function area resources, focus on life care, domestic services, medical rehabilitation, spiritual comfort, legal aid, such as pension services that occupy the home, a home endowment embody characteristics, demand docking with the service, all kinds of service resources configuration relatively complete home endowment service system, make the elderly can effectively solve practical difficulties that occupy the home, life and medical services to get basic guarantee.

\subsection{Improved the Diversified Home-Based Old-Age Care Service Model}

The government should support based on community social forces to run home pension services, pension homemaking company and small endowment institutions, provided by the home endowment service organization or endowment home economics company elderly meal, day care, elderly activity center and other forms of pension services, should continue to expand the service content, carry out comprehensive maintenance, domestic service, life distribution, features such as multiple ways for the old man that occupy the home services [5].

\subsection{Strengthened Home Care Services for Special Groups}

According to the characteristics and needs of the elderly, living alone, disabled and other special groups of the elderly, low compensation and paid services are adopted to provide family care, basic life care, special care, emergency assistance and other services for the elderly in need. At the same time, it further introduces the market mechanism, expands the service field and service mode, and explores the establishment of the classification service method for the special old-age care groups to meet their diverse service needs.

\subsection{Improved the Ranks of Elderly Care Professionals}

The construction of home-based elderly care service team should be built in a comprehensive way. Local governments should strengthen support and professional construction planning for colleges and universities with related majors for the aged, and speed up the training of talents for the aged service. For pension service professional "difficult recruitment of students", "stay" and pension service industry problems, brain drain, the local government should formulate a series of students from the pension to the policy of practitioners to attract students, Suggestions for pension services professional graduates and professionals hierarchical pay one-time entry subsidies and post subsidies, service personnel title appraisal system, establish an open title mutual recognition with other related industries channels, strengthen the pension services of professional appeal.

\section{Multiple Integrated Home Care Service Platform}

Of diversity in unity of pension service platform based on community, supported by information database, the intelligent terminal and the Internet, the in- 
tegration of community endowment service facilities, professional service team, and social resources, focus on building "the archives management, home care, call for aid, health services" as the core of pension service platform that occupy the home, the family pension for the elderly to provide comprehensive services. Effectively integrate social service resources as the service subject, establish a sound home care service system, and create a real sense of "nursing home without walls".

\subsection{Home Care Data Center}

Home care data center is the core of the whole platform. Based on the elderly archives database, it files information, data analysis, information push and health iot from the aspects of providing life care, housekeeping service, medical care, rehabilitation nursing and spiritual comfort and other services for the elderly in community home care. Information filing is mainly about the establishment of early database and the collection of personal information and health data of the elderly. Data analysis includes the application of health information in the platform, automatic data analysis and processing, and provide the results to the health management personnel and provide health intervention guidance and Suggestions; Information push is to grab the personal data of the data center in real time and compare it with the hot content on the Internet, and precisely push the information with high relevance and large fit. Health iot mainly carries out real-time detection and automatic transmission of detection indicators on the basis of the previous items, and coordinates with the smart wearable device SOS call and positioning at the terminal for emergency rescue.

\subsection{Health and Pension Service Center}

As the main body of the whole platform, the health and old-age care service center mainly provides service supply for the health and old-age care of the elderly. According to the physical and living characteristics of the elderly, it mainly provides life care service, medical care service, emergency relief service, housekeeping service, spiritual comfort and other services. Among them, life care services include meal assistance, daily living, bath assistance, cleaning and charge services, etc.; Health care services include preventive health care, medical assistance, rehabilitation care and health counseling services; Emergency relief service is mainly to meet the emergency relief measures and programs taken by the elderly due to emergencies, including whether the corresponding facilities and equipment can ensure that the emergency relief needs are met; Spiritual comfort services include spiritual support and psychological counseling services. By mastering the psychological characteristics and basic communication skills of the elderly, they can observe the emotional changes of the elderly and adjust the psychological state of the elderly through psychological intervention. Housekeeping service is mainly for the elderly because of their own inconvenience and life needed some such as home appliance furniture maintenance and installation 
services, daily life cleaning services and other housekeeping services.

\subsection{Intelligent Terminal Support Equipment}

Home endowment pattern doomed endowment separation of supply and demand, and to realize life pension and attack the effective demand and seamless ration, and all the implementation of endowment service needs of the elderly "call", in the artificial intelligence and Internet era of cloud today, through intelligent terminal equipment and software support to realize endowment and pension service demand of data interaction. For example, the physiological monitoring of the elderly: the basic information of blood pressure, heart rate, ecg and other daily measurements in the elderly at home can be transmitted to the health archive database of the home-based elderly care data center through the intelligent terminal every day, which can provide health monitoring, emergency rescue, security alarm, remote nursing and other services; Health warning: system according to the physiological information, automatic tracking, judgment, the old man body anomalies, when the old man sudden movement disorder, posture is still more than set time limits for doing so, will automatically alarm to health care centers, community health institutions through a remote monitoring system to supervise them, children, warning, community health institutions can timely door-to-door service.

\section{The Final Results}

The diversified and integrated platform realizes the care and service for the elderly in the aspects of "medicine", "food", "conduct", "affection" and "use". Family members can timely understand the elderly situation, to ensure the symmetry of information; pension institutions can allocate pension resources more reasonably through the platform, so as to make full use of limited pension resources. The public can learn about the real-time operation of pension service institutions through the terminal APP, so as to improve the service function of the government for the convenience of the people, and potentially form a group of groups concerned about pension, group policy and group discussion, so as to make pension "grounded", make pension cause healthy and sustainable development, and really effectively alleviate the problem of pension in China. In this paper, resources are effectively integrated to establish a multi-linkage pension service platform. However, the real implementation still needs the multi-party support and integration of systems, policies and technologies, so that the demand and supply of multiple subjects can communicate in time and realize intelligent pension service.

\section{Acknowledgements}

School planning, construction and development center of ministry of education Project "Northeast Sichuan Healthy Industry Cooperative Education Experiment Project Based on the Concept of Active Aging" (No. XN0104A); Sichuan Uni- 
versity of Arts and Sciences in 2018 "Regional Health Industry Block Chain Applied Research" scientific research and innovation team support; the education and teaching research and reform project of Sichuan University of Arts and Sciences 2017 "Path exploration of 'integration of production and education' for application-oriented undergraduate majors-based on empirical analysis of health and nursing majors".

\section{Conflicts of Interest}

The author declares no conflicts of interest regarding the publication of this paper.

\section{References}

[1] China Research Center on Aging and Social Sciences Academic Press (2018) Blue Book on Aging: A Survey on the Living Conditions of the Elderly in Urban and Rural Areas of China, 45-53.

[2] Zhao, Q. (2010) Analysis on the Current Situation and Problems of Community Home Care Mode in China. The South of China Today, 7, 4-6.

[3] Cao, F.L. (2018) The Construction of Community Home Care Service System. Chongqing Social Science, 10, 103-112.

[4] Sun, C.Y. (2018) Thoughts on Building a Multi-Level Pension Service System Based on Home-Based Pension. China's Civil Affairs, 21, 15-16.

[5] Shi, P.P. (2016) Thoughts on Building a Multi-Level Pension Service System Based on Home-Based Pension. New Silk Road, 9, 72-73. 